\title{
PERILAKU PETANI DALAM PEMANFAATAN PUPUK ORGANIK CAIR URINE KELINCI PADA BUDIDAYA BROKOLI (Brassica OleraceaL.)DI KECAMATAN TELAGASARI KABUPATEN KARAWANG
}

\author{
Oleh \\ Nur Azka Oryza Sativa ${ }^{1)}$, Tri Ratna Saridewi ${ }^{2)}$ \& Dayat ${ }^{3)}$ \\ 1,2,3Politeknik Pembangunan Pertanian Bogor; Jl. Arya Suryalaga (d/h Cibalagung) No.1 \\ Kecamatan Bogor Barat Kota Bogor, Telepon :08518312386, fax:02518312386 \\ Jurusan Pertanian, Polbangtan Bogor, Kota Bogor \\ Email: 19zkaoryza13@gmail.com, 2trsdewi74@yahoo.com \& \\ 3drdayatpolbangtan@gmail.com
}

\begin{abstract}
Abstrak
Tujuan penelitian ini adalah mendeskripsikan perilaku petani dalam pemanfaatan pupuk organik cair pada budidaya brokoli, menganalisis faktor-faktor yang berhubungan antara perilaku petani dalam pemanfaatan pupuk organik cair urine kelinci pada budidaya brokoli, dan Mendeskripsikan strategi untuk peningkatan perilaku petani dalam pemanfaatan pupuk organik cair urine kelinci pada budidaya brokoli di Kecamatan Telagasari Kabupaten Karawang. Pengkajian dilakukan pada bulan Maret sampai dengan bulan Juli 2020.sasaran pelaksanaan kajian ini adalah kelompoktani dan petani yang membudidayakan tanaman brokoli yang ada di Desa Linggarsari dan Desa Cariumulya dengan responden 30 orang. Data yang dikumpulkan dalam kajian primer dan data sekunder. Metode yang digunakan adalah analisis deskriptif dan menggunakan korelasi Rank Spearman. Pengetahuan petani dalam Perilaku Petani Dalam Pemanfaatan Pupuk Organik Cair Urine Kelinci Pada Budidaya Brokoli (Brassica Oleracea L.) Di Kecamatan Telagasari Kabupaten Karawang tergolong kedalam kategori sedang dengan jumlah 33,84\%, karena sumber informasi yang diperoleh petani sangat terbatas, petani hanya mengandalkan informasi yang bersumber dari penyuluh dan pengalaman pribadi, itu juga tidak semua dapat diserap oleh petani dengan baik. Sikap petani terhadap perilaku petani dalam pemanfaatan pupuk organik cair urine kelinci masih tergolong sedang dengan jumlah $28,86 \%$, hal ini dikarenakan masih banyak petani yang belum menerapakan teknologi pemanfaatan pupuk organik cair urine kelinci ini. Karakteristik perilaku petani yang terakhir adalah keterampilan hasil analisis data yang telah dilakukan menunjukan bahwa tingkat keterampilan petani sudah tergolong tinggi dengan jumlah $35,62 \%$. Hal ini dikarenakan pada umumnya petani sudah mengenal bagaimana cara pelaksanaan budidaya tanaman brokoli karena mayoritas petani di Kecamatan Telagasari khususnya Desa Linggarsari dan Desa Cariumulya adalah petani brokoli.
\end{abstract}

Kata Kunci : Perilaku Petani \& Tingkat Pupuk Organik Cair Urine Kelinci.

\section{PENDAHULUAN}

Penggunaan pupuk kimia yang mencapai $60 \%$ data ini dari programa Kecamatan Telagasari dan terus menerus mengakibatkan dampak negatif bagi tanah dan lingkungan. Dampak negatif yang timbul merusak struktur (fisik) tanah dan lingkungan, karena tanah menjadi keras pada musim kering dan lengket pada musim hujan dengan porositas tanah menurun. Pupuk anorganik tidak mempunyai sifat yang dapat memperbaiki sifat dan fungsi fisik tanah serta fungsi biologi tanah secara langsung.

Meningkatnya kesadaran akan kesehatan telah menyebabkan meningkatnya trend (populer) tanaman organik yang mengakibatkan penggunaan pupuk organik terdiri dari limbah hasil pertanian berupa sisa tanaman, hasil pertanian, pupuk hijau, pupuk kandang, dan limbah kota. 
Permintaan pupuk organik yang semakin tinggi dari unggas maupun ruminansia sehingga semakin sulit diperoleh karena harganya semakin mahal. Untuk mengatasi masalah ini salah satu alternatif penggunaan urine kelinci. Urine kelinci dikenal sebagai sumber pupuk organik cair yang potensial untuk tanaman hortikultura.

Ketersediaan urine kelinci tidak seperti kotoran ternak lainnya, namun daerah-daerah tertentu telah memanfaatkan untuk beberapa jenis tanaman penggunaan urine kelinci dibandingkan dengan kotoran ayam pada berbagai sayuran di Kecamatan Telagasari Kabupaten Karawang.

Kondisi demikian, maka diperlukan suatu upaya untuk membantu kelancaran pembangunan pertanian. Penyuluh pertanian menurut Mardikanto (1993) adalah proses perubahan perilaku (pengetahuan, sikap, dan keterampilan) dikalangan petani, agar mereka mau, tahu dan mampu melaksanakan perubahan-perubahan dalam usahataninya demi terciptanya peningkatan produksi. Tujuan penyuluh pertanian adalah mengubah perilaku petani agar dapat mengubah perilaku petani dalam berusahatani yang lebih baik.

Berdasarkan latar belakang diatas, rumusan masalah yang dapat diambil dari dikajian yaitu:

1. Bagaiamana perilaku petani dalam pemanfaatan pupuk organik cair urine kelinci pada budidaya brokoli(Brassica Oleracea L) di Kecamatan Telagasari Kabupaten Karawang Provinsi Jawa Barat ?

2. Faktor-faktor apa saja yang berhubungan dengan perilaku petani dalam pemanfaatan pupuk organik cair urine kelinci pada budidaya brokoli( Brassica Oleracea L) di Kecamatan Telagasari Kabupaten Karawang Provinsi Jawa Barat?

3. Bagaimana Strategi untuk meningkatan perilaku petani dalam pemanfaatan pupuk organik cair urine kelinci pada budidaya brokoli(Brassica Oleracea L) di Kecamatan Telagasari Kabupaten Karawang Provinsi Jawa Bara

\section{Kerangka Berpikir}

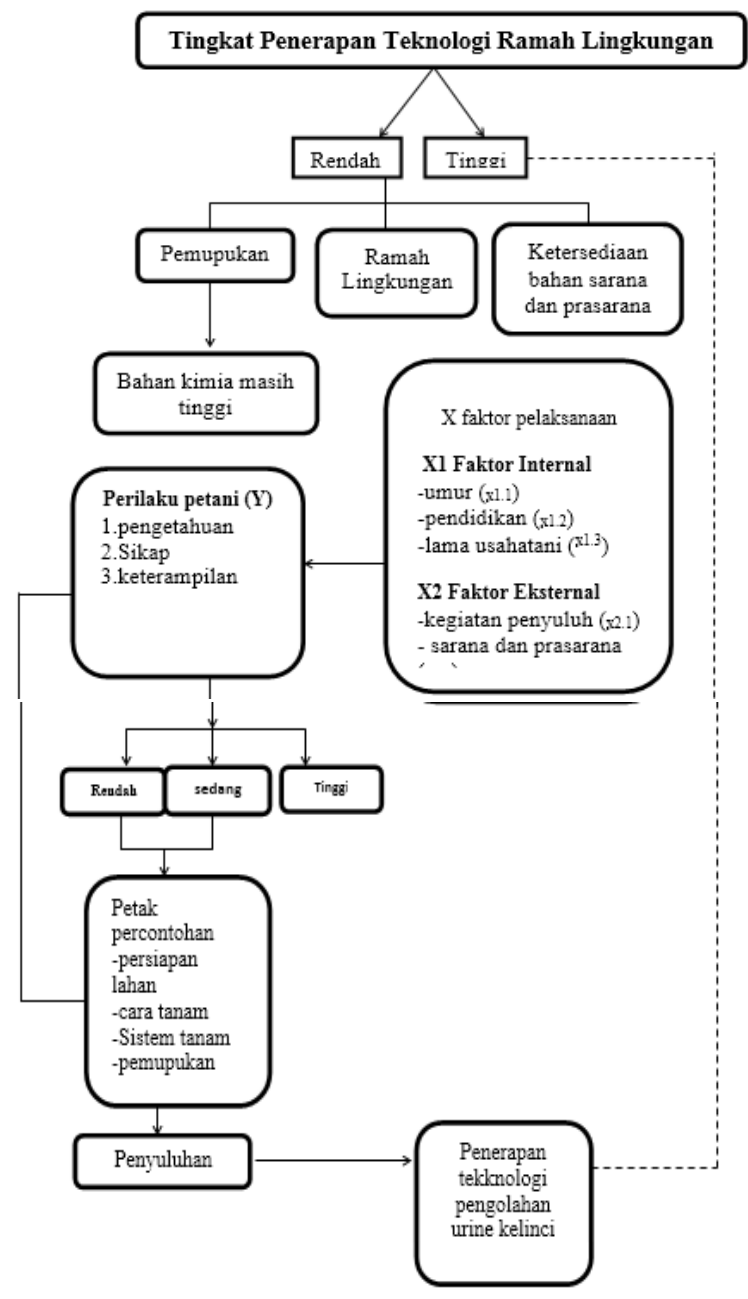

\section{METODE PENELITIAN}

Waktu pelaksanaan kegiatan kajian Tugas Akhir dilaksanakan selama empat bulan, terhitung dari bulan Maret sampai dengan bulan Juli. Selanjutnya tempat pelaksanaan kegiatan kajian Tugas Akhir ini dilaksanakan di Desa Linggarsari dan Desa Cariumulya di Kecamatan Telagasari Kabupaten Karawang Provinis Jawa Barat. Supaya penelitian ini dapat sesuai dengan populasi dan sampel yang diambil harus bersifat representatif, artinya sampel haruslah mencerminkan dan bersifat mewakili keadaan populasi. Jumlah sampel pada pengkajian ini sebanyak 30 orang. Data yang akan dibutuhkan dalam pengkajian ini meliputi data primer dan data sekunder yang bersifat kualitatif dan kuantitatif.

Uji validitas ini dilaksanakan dengan cara mengujikan instrumen atau kuesioner dengan 
format dan isi yang sama kepada petani lain dengan karakteristik yang sama dengan petani yang menjadi responden. Adapun petani yang dijadikan sebagai responden dalam pengujian validitas ini berjumlah 30 orang petani yang berada di Desa Linggarsari dan Desa Cariumulya Kecamatan Telagasari Kabupaten Karawang. Uji reabilitas telah dilaksanakan dari kuesioner 50 pernyataan/pertanyaan Realibel.

Analisis data yang digunakan dalam pengkajian ini adalah analisis deskriptif. Analisis deskriptif digunakan untuk mengukur sejauh mana Perilaku Petani Dalam Pemanfaatan Pupuk Organik Cair Pada Budidaya Brokoli Berikut adalah penggunaan analisis data berdasarkan tujuan :

\section{Tujuan pertama mendeskripsikan perilaku petani}

Tingkat perilaku petani dianalisis menggunakan analisis deskriptif dengan menentukan nilai rata-rata hitung, presentasi atau proposi data dan pengelompokan data, data yang dianalisis adalah data ordinal berupa skala likert. Modifikasi dengan empat pilihan jawaban dengan presentase nilai 1 sampai 4 . Selanjutnya jawaban responden dikelompokan menjadi tiga kategori dan diinterpretasikan.

2. Tujuan kedua untuk menganalisis yang berhubungan dengan perilaku petani dalam pemanfaatan limbah urine kelinci menjadi pupuk organik cair pada budidaya brokoli.

Analisis korelasi yang akan digunakan yaitu analisis statistik uji korelasi Rank Spearman dengan menggunakan progaram komputer SPPS atau Microsoft Excel. Analisis korelasi digunakan untuk melihat hubungan antara faktor internal dengan perilaku petani sehingga berdampak pada penggunaan pupuk organik di Kecamatan Telagasari. Rumus Korelasi Spearman :

$$
R=1-\frac{6 \sum \mathrm{d} 2}{N(\mathrm{n} 2-1)}
$$

Dimana :

Rs $=$ Nilai korelasi rank Spearman $\mathrm{d} 2=$ Selisih setiap pasang rank

$\mathrm{N}=$ Jumlah pasangan rank

3. Tujuan ketiga untuk mendeskripsikan strategi untuk peningkatan perilaku petani dalam pemanfaatan pupuk organik cair urine kelinci pada budidaya brokoli.

Strategi peningkatan penyuluhan perilaku petani hanya dideskriptifkan atau digambarkan sesuai dengan strategi yang ada seperti petak percontohan. Teknik analisis deskriptif dengan menggunakan petak percontohan dan kegiatan penyuluhan untuk mengetahuin tujuan ketiga. Petak percontohan yang dimulai dari penanaman, pemeliharaan dan pemupukan yang sebagai ancuan dari judul diatas dan luas lahan yang digunakan yaitu $500 \mathrm{~m} 2$ dengan dua perlakuan. Dengan adanya petak percontohan ini bisa meyakinkan petani begitu banyaknya manfaatnya dari pupuk organik cair urine kelinci dan memberikan informasi kepada petani.

\section{HASIL DAN PEMBAHASAAN}

Karakteristik responden merupakan latar belakang keadaan dari responden sebagai tanggapan dan merupakan langkah selanjutnya untuk melaksanakan pengkajian yang lebih mendalam. Responden sebagai sampel dalam kegiatan pengkajian ini adalah petani brokoli yang merupakan anggota kelompoktani. Karakteristik responden yang dianalisis adalah umur, tingkat pendidikan formal dan lama berusaha tani. Hasil wawancara terhadap 30 responden di Desa Linggarsari dan di Desa Cariumulya diperoleh hasil karakteristik responden sebagai berikut :

Tabel 1. Karakteristik Responden

\begin{tabular}{|c|c|l|c|c|}
\hline \multirow{2}{*}{ No } & \multicolumn{3}{|c|}{ Persentase Karakteristik Responden } \\
\cline { 2 - 5 } & $\begin{array}{c}\text { Karakteristi } \\
\mathrm{k}\end{array}$ & \multicolumn{1}{|c|}{ Kategori } & $\begin{array}{c}\text { Jumlah } \\
\text { (orang) }\end{array}$ & $\begin{array}{c}\text { Persentase } \\
(\%)\end{array}$ \\
\hline 1. & Umur & $\begin{array}{l}\text { Belum } \\
\text { Produktif (0 - } \\
\text { 20) }\end{array}$ & - & - \\
\hline \multirow{2}{*}{ (Tahun) } & $\begin{array}{l}\text { Produktif ( 20- } \\
63)\end{array}$ & 25 & 90,32 \\
\hline & $\begin{array}{l}\text { Tidak } \\
\text { Produktif (> } \\
64)\end{array}$ & 5 & 9,68 \\
\hline
\end{tabular}




\begin{tabular}{|c|c|c|c|c|}
\hline \multicolumn{3}{|c|}{ Jumlah } & \multirow{2}{*}{$\begin{array}{l}30 \\
20\end{array}$} & \multirow{2}{*}{$\begin{array}{c}100 \\
41,94\end{array}$} \\
\hline 2. & $\begin{array}{l}\text { Pendidikan } \\
\text { Formal }\end{array}$ & $\mathrm{SD} /$ sederajat & & \\
\hline & & $\begin{array}{l}\text { SLTP / } \\
\text { sederajat }\end{array}$ & 5 & 29,03 \\
\hline & & $\begin{array}{l}\text { SLTA / } \\
\text { sederajat }\end{array}$ & 3 & 22,58 \\
\hline & & $\begin{array}{l}\text { Perguruan } \\
\text { Tinggi }\end{array}$ & 2 & 6,45 \\
\hline \multicolumn{3}{|c|}{ Jumlah } & 30 & 100 \\
\hline 3. & $\begin{array}{l}\text { Lama } \\
\text { berusaha } \\
\text { Tani }\end{array}$ & Rendah $(<11)$ & 15 & 35,48 \\
\hline & (Tahun) & $\begin{array}{l}\text { Sedang }(11- \\
15)\end{array}$ & 8 & 6,45 \\
\hline & & Tinggi $(>15)$ & 7 & 58,07 \\
\hline \multicolumn{3}{|c|}{ Jumlah } & 30 & 100 \\
\hline
\end{tabular}

Sumber : Data primer diolah oleh penulis 2020

Menurut Widyastuti dkk (2014) dalam Baharsyah (2019) umur responden dibagi menjadi 3 kategori yaitu produktif ( 20-63), tidak produktif $(>64)$, dan belum produktif ( 0 20). Tingkat pendidikan formal responden dibagi menjadi 4 kategori yaitu sangat tinggi (SD/sederajat) , tinggi (SLTP / Sederajat), sedang (SLTA / Sederajat), dan rendah (Perguruan Tinggi). Dan tingkat lama berusahatani responden dibagi menjadi 3 kategori yaitu rendah $(<11)$, sedang (11-15), dan tinggi $(>15)$

Kategori perilaku petani

Kategori perilaku petani yang diamati dalam kajian ini terdiri dari beberapa variabel diantaranya : pengetahuan, sikap, dan keterampilan. Data kategori perilaku petani disajikan berikut :

\section{Tabel 2. Kategori Perilaku Petani}

\begin{tabular}{|c|l|c|c|c|}
\hline No & Kategori & Pengetahuan & Sikap & Keterampilan \\
\hline 1. & $\begin{array}{l}\text { Kurang } \\
\text { baik }\end{array}$ & $15-25$ & $10-20$ & $15-25$ \\
\hline 2. & $\begin{array}{l}\text { Cukup } \\
\text { baik }\end{array}$ & $>25-33$ & $\begin{array}{c}>20- \\
30\end{array}$ & $>25-33$ \\
\hline 3. & $\begin{array}{l}\text { Sangat } \\
\text { baik }\end{array}$ & $>33-45$ & $\begin{array}{c}>30- \\
40\end{array}$ & $>33-45$ \\
\hline
\end{tabular}

Sumber : Data primer diolah oleh penulis tahun 2020

Setelah dilaksanakan pengkategorikan perilaku petani, selanjutnya dilaksanakan distribusi kategori perilaku petani dapat diketahui dan dinyatakan dalam kategori kurang baik, cukup baik, dan sangat baik. Berikut adalah distribusi kategori perilaku petani.

Tabel 3. Karakteristik Perilaku Petani

\begin{tabular}{|l|l|c|c|}
\hline No & $\begin{array}{c}\text { Karakteristik } \\
\text { Perilaku Petani }\end{array}$ & Jumlah & Keterangan \\
\hline 1. & Pengetahuan & 33,84 & Kurang baik \\
\hline 2. & Sikap & 28,86 & Cukup baik \\
\hline 3. & Keterampilan & 35,62 & Sangat baik \\
\hline
\end{tabular}

Sumber : Data primer diolah oleh penulis tahun 2020

Dapat dilihat bahwa mayoritas petani dalam perilaku petani masuk kedalam kategori sangat baik yaitu sebanyak 30 responden dengan presentase 35,62\% dari jumlah seluruh responden berdasarkan data diatas petani lebih cukup dalam keterampilan perilaku petani dalam pemanfaatan pupuk organik cair pada budidaya brokoli.

\section{Hubungan Perilaku Petani Dalam Pemanfaatan Pupuk Organik Cair Urine Kelinci Pada Budidaya Brokoli}

Hasil pengkajian menunjukan bahwa hubungan antara perilaku petani yang meliputi pengetahuan, sikap, dan keterampilan petani terhadap penerapan teknologi pemanfaatan pupuk organik cair urine kelinci menghasilkan hubungan yang nyata. Distribusi hubungan perilaku petani dengan pemanfaatan pupuk organik cair urine kelinci pada budidaya brokoli dapat berikut ini.

Tabel 4. Hubungan Perilaku Petani

\begin{tabular}{|l|c|c|c|c|}
\hline $\begin{array}{c}\text { Perilaku } \\
\text { Petani }\end{array}$ & $\begin{array}{c}\text { Sig. } \\
(2-t a i l e d)\end{array}$ & Korelasi & Ket. & $\begin{array}{c}\text { Tingkat } \\
\text { Hubungan }\end{array}$ \\
\hline $\begin{array}{l}\text { Pengetah } \\
\text { uan }\end{array}$ & 0,000 & $0,610^{\times *}$ & $\begin{array}{c}\text { Ada } \\
\text { hubungan }\end{array}$ & $\begin{array}{c}\text { Hubungan } \\
\text { kuat }\end{array}$ \\
\hline Sikap & 0,000 & $0,639^{* \times}$ & $\begin{array}{c}\text { Ada } \\
\text { hubungan }\end{array}$ & $\begin{array}{c}\text { Hubungan } \\
\text { kuat }\end{array}$ \\
\hline $\begin{array}{l}\text { Keteramp } \\
\text { ilan }\end{array}$ & 0,000 & $0,635^{\times *}$ & $\begin{array}{c}\text { Ada } \\
\text { hubungan }\end{array}$ & $\begin{array}{c}\text { Hubungan } \\
\text { kuat }\end{array}$ \\
\hline
\end{tabular}

Sumber: Data primer diolah oleh penulis tahun 2019

Berdasarkan tabel diatas menunjukam bahwa hubungan antara perilaku petani yang meliputi pengetahuan, sikap, dan keterampilan memiliki ada hubungan dan tingkat hubungan kuat yaitu sebanyak 30 responden.

Faktor - faktor yang berhubungan dengan perilaku petani dalam pemanfaatan pupuk organik cair urine kelinci pada budidaya brokoli Faktor-faktor yang berhubungan dengan perilaku petani pada kajian ini ada tujuh antara lain; umur, tingkat pendidikan formal, Lama Berusahatani,dan Faktor Eksternal. berikut: 
Tabel 5. R-Square

\begin{tabular}{|c|c|c|c|c|}
\hline Model & $\mathrm{R}$ & $\begin{array}{c}\mathrm{R} \\
\text { Square }\end{array}$ & $\begin{array}{c}\text { Adjusted } \\
\text { R Square }\end{array}$ & $\begin{array}{c}\text { Std. Error } \\
\text { of the } \\
\text { Estimate }\end{array}$ \\
\hline 1 & $.999^{\mathrm{a}}$ & .998 & .944 & 4.08176 \\
\hline
\end{tabular}

Sumber: Data Olah Primer SPSS

Berdasarkan tabel diatas besarnya RSquare sebesar 0,998 menunjukkan bahwa 99,8 $\%$ perilaku petani dihubungkan oleh dua variabel independen yaitu pada karakteristik responden dan perilaku petani. Sedangkan hasil uraian Anova dan F test, diperoleh F hitung sebesar 385,160 dengan signifikansi 0,000 .

Tabel 6. Variabel perilaku petani

\begin{tabular}{|c|l|l|l|l|}
\hline No & Variabel & Sig. & $\begin{array}{l}\text { Koefisien } \\
\text { korelasi }\end{array}$ & Keterangan \\
\hline 1. & Umur $\left(\mathrm{X}_{1.11}\right.$ & 0,224 & 0,175 & $\begin{array}{l}\text { Tidak ada } \\
\text { hubungan } \\
\text { Tidak ada } \\
\text { hubungan }\end{array}$ \\
\hline 2. & Pendidikan $\left(\mathrm{X}_{1.2}\right)$ & 0,125 & 0,220 & Hubungan \\
\hline 3. & $\begin{array}{l}\text { Lamaberusahatani }(\mathrm{X} \\
1.3)\end{array}$ & 0,000 & 0,560 & Hubungan \\
\hline 4. & Faktor eksternal $\left(\mathrm{X}_{2}\right)$ & 0,000 & 0,650 & \multicolumn{2}{|c|}{} \\
\hline
\end{tabular}

Strategi meningkatkan perilaku petani

Pengalaman lama berusahatani yang cukup lama > 15 tahun yang memiliki hubungan. Dengan perincian faktor yang berhubungan dengan perilaku petani memiliki $>15$ tahun dan < 11 tahun. Umumnya mereka memperoleh lama berusahatani secara turun menurun dari orangtua mereka. Kondisi ini juga bisa dihubungkan untuk produktivitas dan keberhasilan lama berusahatani akan lebih mudah untuk meningkatkan produktivitas lama berusahataninya. Hal ini menunjukan bahwa semakin lama berusahatani yang didapatkan dalam berusahatani semakin baik pemahaman dalam perilaku petani dalam pemanfaatan pupuk organik cair urine kelinci pada budidaya brokoli. Sedangkan untuk lama berusahatani yang baru juga besarnya sama dengan petani yang mendapatkan pengalaman, hal ini dimungkinkan daerah tersebut masih dalam tahap memunculkan lagi semangat petani dalam lama berusahatani.

\section{Tabel 7. Jadwal kegiatan penyuluhan}

\begin{tabular}{|c|c|c|c|c|c|}
\hline No & $\begin{array}{c}\text { Hari/ } \\
\text { Tanggal }\end{array}$ & $\begin{array}{c}\text { Sasaran } \\
\text { (Kelompokt } \\
\text { ani)/ } \\
\text { Alamat }\end{array}$ & Materi & Metode & Media \\
\hline 1 & 2 & 3 & 4 & 5 & 6 \\
\hline 1. & $\begin{array}{c}10 \text { Juni } \\
2020\end{array}$ & $\begin{array}{l}\text { Sri Jaya, } \\
\text { Desa } \\
\text { Linggarsari }\end{array}$ & $\begin{array}{c}\text { 1.Cara } \\
\text { pembuatan } \\
\text { pupuk }\end{array}$ & $\begin{array}{c}\text { Ceramah } \\
\text { dan }\end{array}$ & Video \\
\hline
\end{tabular}

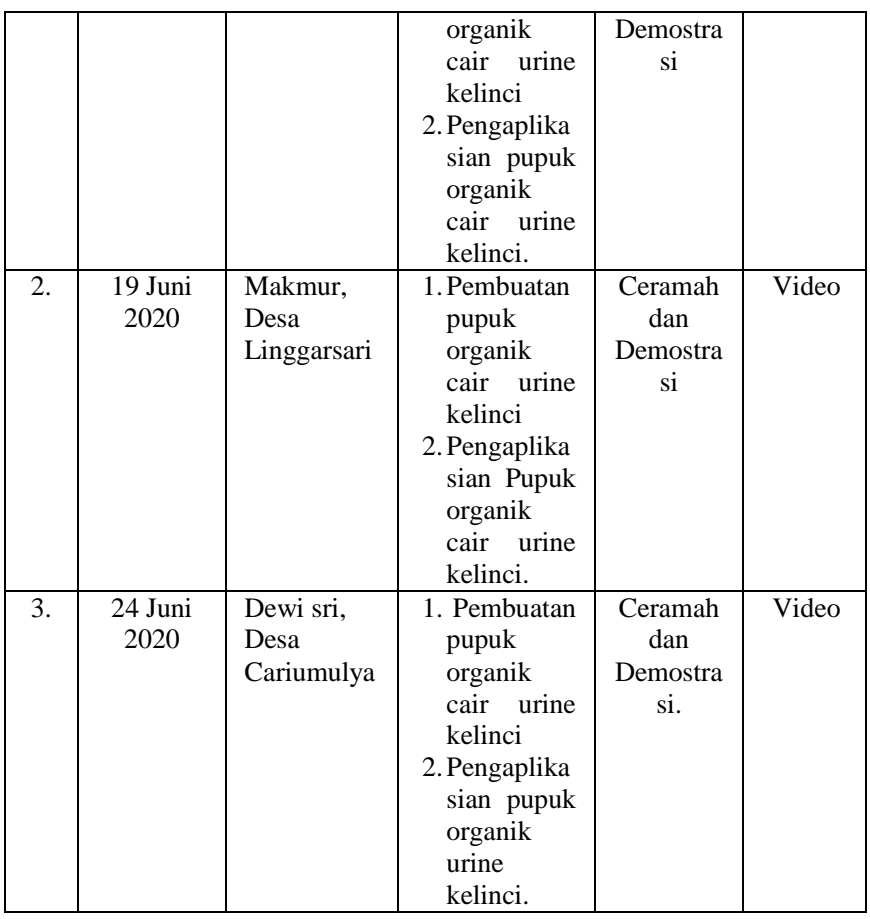

Sumber : Data Primer diolah penulis, 2020 Pelaksanaan Petak Percontohan

Untuk lebih menguatkan materi yang disampaikan dalam kegiatan penyuluhan selanjutnya dilaksanakan pembuatan petak percontohan. Petak percontohan yang dilaksanakan adalah mulai dari penanaman tanaman brokoli dilanjut dengan pemanfaatan pupuk organik cair urine kelinci. Petak percontohan dilaksanakan di Poktan Sri Jaya. Lahan yang digunakan untuk pembuatan petak percontohan yaitu seluas $1000 \mathrm{~m} 2$, yang dimana $500 \mathrm{~m} 2$ menggunakan pupuk organik kotoran kambing yang kebiasaan petani dan 500m2 menggunakan pupuk organik cair urine kelinci.

Tujuan dari pembuatan petak percontohan ini adalah untuk membandingkan proses dan hasil dari kegiatan budidaya tanaman brokoli yang menerapakan teknologi pemanfaatan pupuk organik cair urine kelinci dengan yang tidak menerapkan atau dengan kata lain sesuai dengan kebiasaan petani.

Dalam pembuatan demplot ini dibuat parameter untuk mengidentifikasi pertumbuhan dari kedua perlaku penanaman. Parameter pengamatan digunakan untuk melihat pertumbuhan dan perkembangan tanaman.

Parameter yang digunakan adalah sebagai berikut : 
1. Pertumbuhan tanaman secara fisiologi yang meliputi jumlah daun yang dihitung atau diamati setiap satu minggu sekali.

2. Pengamatan populasi hama yang meliputi keberadaan dan kelimpahan hama yang menyerang.

Tabel 8. Jumlah Daun Pada Tanaman

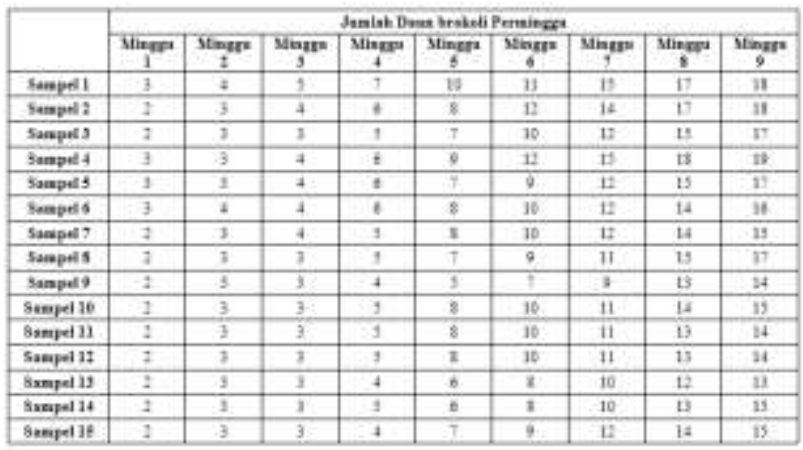

Dari kesimpulan hasil petak percontohan dapat disimpulkan bahwa perilaku petani dalam pemanfaatan pupuk organik cair urine kelinci layak untuk digunakan petani dalam berbudidaya tanaman, dengan dilihat dari beberapa perbandingan yang menyatakan bahwa pupuk organik cair urine kelinci lebih baik dibandingkan dengan budidaya konvensional pada umumnya. Akan tetapi, berdasarkan hasil wawancara dengan beberapa Ketua Kelompok Tani, mereka berpendapat berkeinginan untuk menggunakan Pupuk organik cair urine kelinci, namun masih jarang digunakan karena biaya yang dikeluarkan untuk menggunakan pupuk organik cair urine kelinci yang ada di toko pertanian.

\section{PENUTUP}

\section{Kesimpulan}

Setelah dilaksanakan kegiatan pengkajian tentang perilaku petani dalam pemanfaatan pupuk organik cair urine kelinci pada budidaya brokoli di Kecamatan Telagasari Kabupaten Karawang, dapat diambil beberapa kesimpulan sebagai berikut :

1. Perilaku petani dalam pemanfaatan pupuk organik cair urine kelinci pada budidaya brokoli di Kecamatan Telagasari tergolong kedalam kategori cukup baik untuk variabel pengetahuan dan sikap, sedangkan untuk keterampilan sudah sangat baik karena petani sudah biasa melakukan pemupukan pada tanaman brokoli.

2. Faktor - faktor yang berhubungan perilaku petani dalam pemanfaatan pupuk organik cair urine kelinci pada budidaya brokoli adalah adanya hubungan untuk lama berusahatani signifikan 0,000 dengan korelasi 0,560 dan faktor eksternal signifikan 0,000 dengan korelasi 0,650 .

3. Strategi yang dapat dilakukan untuk meningkatkan perilaku petani dalam pemanfaatan pupuk organik cair urine kelinci pada budidaya brokoli di Kecamatan Telagasari adalah memberikan penyuluhan melalui penyediaan informasi (penyebaran leaflet, video, dan petak penyuluhan) dengan memperhatikan umur, pendidikan, lama berusahatani, dan faktor eksternal. Untuk meningkatkan strategi yaitu lama berusahatani yang memiliki hubungan.

\section{Saran}

Selanjutnya saran yang dapat disampaikan dalam kegiatan pengkajian ini adalah agar penyuluhan lebih efektif maka penyuluhan dapat menunjuk petani yang lebih senior, memiliki pengalaman yang cukup ahli, dan berpendidikan tinggi menjadi acuan untuk menyampaikan kembali hasil penyuluhan kepada petani yang lebih muda, petani pemula, dan petani yang berpendidikan rendah. Petani tidak ketinggalan informasi.

\section{DAFTAR PUSTAKA}

[1] Adiyoga, W. 1986. An index of management for brocoli farms in Wonosobo Central of Java. Buletin Penelitian Hortikultura XXVI(4): 21-32.

[2] Amali, N. 2014. Demonstrasi Teknologi Metode Penyuluhan yang bersentuhan 
Langsung dengan Petani. Banjarbaru :

BPTP Kalimantan Selatan.

[3] Amirin, Tatang M. 2011. Populasi dan sampel

penelitian.Tatangmanguny.wordpress.com

[4] Anonim. 2001. Kubis Bunga dan Brokoli.

Kanisius. Yogyakarta.

[5] Adamson, K. A. \& Prion, S.. (2013). Reliability : measuring internal consistency using cronbach's $\alpha$, Clinical Simulation in Nursing, 9, hlm. 179-180.

[6] BPP Telagasari. 2019. Programa Kecamatan Telagasari 2019. Karawang : Balai Penyuluhan Pertanian Kecamatan Telagasari.

[7] BPS. 2019. Kabupaten karawang dalam Angka 2019. Karawang : Badan Pusat Statistik Kabupaten Karawang.

[8] Dewi, I. N dan Awang, S. A. 2018. Karakteristik Petani dan Kontribusi Hutan Kemasyarakatan (HKm) Terhadap Pendapatan Petani di Kulon Progo. Makasar : 1Balai Litbang Lingkungan Hidup dan Kehutanan 


\section{HALAMAN INI SENGAJA DIKOSONGKAN}

